\title{
Investigation of immunity against Bordetella pertussis in pregnant women and an overview of the vaccination schedule in Turkey
}

\author{
Serdar Gül ${ }^{1 \oplus}$, Cemile Sönmez ${ }^{2 \oplus}$, Gökçe Ayvaz ${ }^{1 \oplus}$, Selçuk Kıllıç \\ ${ }^{1}$ Department of Infectious Diseases and Clinical Microbiology, Kırıkkale University Faculty of Medicine, Kırlkkale; ${ }^{2}$ Department of \\ Microbiology Reference Laboratories and Biological Products, Ministry of Health, General Directorate of Public Health, Ankara, Turkey.
}

\begin{abstract}
Background. Pertussis caused by Bordetella pertussis, is a disease leading to significant morbidity and mortality in neonates and infants. Direct protection of the infant may be achieved by maternal and neonatal vaccination. Despite primary vaccination, infants under six months pose the greatest risk of infection with pertussis. Maternal immunization provides a high level of infant protection from birth until immunity is achieved by active vaccination. There is no routine Tdap vaccination recommendation for pregnant women in Turkey. This study was carried out to determine pertussis antibody levels in pregnant women and provide data for improving vaccine planning.

Methods. The study was carried out with 133 pregnant women in Turkey. Antibody titers to pertussis toxin (anti-PT) and filamentous hemagglutinin (anti-FHA) were measured by the commercially available ELISA.

Results. Among 133 participants, 93 (69.9\%) were found to be immune according to anti-PT IgG antibody levels. According to anti-FHA IgG antibody levels, 123 (92.5\%) participants were considered to be immune. A positive correlation was observed between PT and FHA and the findings were statistically significant $(P<0.001, \mathrm{r}=$ 0.343). In the study group, the ages of the participants varied between 17 and 44 years. The mean age of those who were immune was $27.3 \pm 5.6$, the mean age of non-immune patients was $29.1 \pm 6.2$ and the difference was not statistically significant $(P=0.14)$.

Conclusions. Our results reveal that approximately one-third of pregnant women were not immune to pertussis, reflecting many young infants to be vulnerable to pertussis infection until the onset of primary vaccinations, although childhood pertussis vaccination coverage has been high for a long time. We conclude that Tdap vaccine recommendation for pregnant women regardless of previous immunization history may be beneficial for the protection of infants in their first six months.
\end{abstract}

Key words: pertussis, vaccine, pregnant women, antibodies, seroprevalence.

Pertussis is a highly infectious vaccinepreventable disease caused by Bordetella pertussis. ${ }^{1}$ Although the incidence of the disease has decreased drastically after the introduction of the whole cell vaccine in the 1940s, pertussis remains a major health problem worldwide. Despite high vaccination coverage, a resurgence of pertussis was observed in some parts of the

Selçuk Kılıç

selcuk.kilic@sbu.edu.tr

Received 14th December 2020, revised 2nd March 2021, 28th April 2021, accepted 13th May 2021. world in the 1980 and 1990s owing to improved surveillance, waning immunity, bacterial evolution, and the usage of sub potent vaccines. ${ }^{2}$ The resurgence of pertussis has led to increased morbidity and mortality in infants too young to be vaccinated. ${ }^{2,3}$

The World health organization (WHO) estimates diphtheria-tetanus-pertussis $\left(\mathrm{DTaP}_{3}\right)$ immunization coverage at $86 \%$ worldwide, reaching more than $90 \%$ in $129(66 \%)$ of the 194 WHO member states. ${ }^{4,5}$ In Turkey, the pertussis vaccine is administered at the ages of 2, 4, 6, 12$24^{\text {th }}$ months and at the first year of elementary 
school (5-6 years of age) as acellular pertussis vaccine with a total of 5 doses resulting in $98 \%$ $\mathrm{DTaP}_{3}$ vaccination coverage in 2018. In Turkey, maternal vaccination with a tetanus toxoid (TT) was started in 1994 and TT was replaced with the tetanus-diphtheria $(\mathrm{Td})$ vaccine in 2004. Currently, $\mathrm{Td}_{2}$ vaccine coverage among pregnant women reached $52 \%$ in 2018., Acceptable immunity is likely to be achieved one month after the completion of primary vaccination, which means infants younger than 5-7 months are partly susceptible to pertussis. ${ }^{8,9}$ Infants of this age category are at relatively high risk for pertussis-related morbidity and mortality and a majority of pertussis-related deaths occur in infants younger than 3 months old. ${ }^{10,11}$ Therefore, preventive measures at this age are crucial and maternal immunization is the most effective measure to protect neonates who are vulnerable to pertussis infection. ${ }^{12-14}$ On the other hand, booster doses of pertussis vaccine in adolescents and adults are required to prevent the disease, as the immunity that occurs after the disease is passed naturally or vaccinated against the disease decreases within 4-5 years. ${ }^{1,15,16}$

There is a highly significant correlation between the level of anti-Pertussis Toxin IgG antibody in the serum and protection against pertussis. ${ }^{13,15-18}$ However, maternal antibody levels are generally low even in the post-vaccine era, so there is no protective level of antibody transmission, and newborns may remain unprotected. ${ }^{16-23}$ In clinical studies, acellular pertussis vaccine during pregnancy has been shown to increase the IgG titers in the mother and the IgG titers transferred to the fetus. Consequently, pertussis risk of newborns tends to decrease. ${ }^{12,16}$ Recently, maternal immunization with Tdap has been recommended in several countries such as the USA, the United Kingdom, Argentina, Belgium, Israel and New Zealand.,11,23 The Advisory Committee on Immunization Practices (ACIP) has also recommended that pregnant women receive Tdap that should be repeated in every subsequent pregnancy as of October 2012. ${ }^{3}$ Tdap is not routinely recommended for pregnant women in Turkey and data on the immune status against pertussis and the level of antibodies in pregnant women are extremely limited..$^{19,23}$ The aim of this study was to determine pertussis antibody levels in pregnant women in a city representative of the Turkish population for vaccine planning.

\section{Material and Methods}

\section{Patient Population}

The study protocol was approved by the Clinical Research Ethics Committee of Kirıkkale University, 01/16.01.2020. The study was conducted in Kirikkale, which is located in central Anatolia and $70 \mathrm{~km}$ east of Ankara, the capital of Turkey. Kırıkkale demographics represents the typical characteristics of a Turkish city with a population of about 300,000 . Based on the information from Kirıkkale Provincial Health Directorate, there were 1262 pregnant women in Kirıkale. The minimum sample size that should be taken with a minimum $\% 10$ seronegativity estimation and within the 95\% confidence interval was calculated as 125 with the Openepi program. In this study, 133 patients who applied to Kırıkkale University Faculty of Medicine between the dates of 16.01.2020 and 16.06.2020 for routine control in the first trimester of their pregnancies were included. Inclusion criteria were: being pregnant and accepting to participate in the study, exclusion criteria: refusal to participate in the study, a history of disease or medication that suppresses the immune system, having symptoms of acute pertussis disease such as cough, fever and shortness of breath.

After obtaining written consent from the patient, a $5 \mathrm{ml}$ of blood sample was drawn and the samples were centrifuged at $1500 \mathrm{rpm}$ for 15 minutes. Separated serum samples were stored at $-20^{\circ} \mathrm{C}$ until the study date. Laboratory work was carried out using the commercial ELISA test in the General Directorate of Public Health, Microbiology Reference Laboratories and Biological Products Department, National 
Vaccine Preventable Bacterial Diseases Serology Laboratory. In addition, data on patients' age, education level, occupation, number of pregnancies, childhood vaccine and Tdap vaccine records, presence of whooping cough, and presence of immunosuppressed individuals or individuals under 1 year old in the same house was collected.

\section{Laboratory Tests}

Pertussis Toxin (PT) and Filamentous Hemagglutinin (FHA) IgG antibodies were studied with the commercially available ELISA test. Pertussis Toxin IgG antibodies were studied with the Nova Lisa Bordetella pertussis IgG kit (NovaTec Immundiagnostica $\mathrm{GmbH}$, Germany). The results were evaluated in terms of the Nova Tec Unit (NTU). Antibody> 11 NTU was considered to be a protective level and $\leq 11$ was considered as a non-protective antibody level. The sensitivity of the kit was $98.3 \%$ with a specificity of $93.0 \%$.

FHA IgG antibodies were studied with Demeditec Bordetella pertussis FHA IgG ELISA kit (Demeditec Diagnostics, Germany). Antibody levels >25 IU / $\mathrm{ml}$ were considered protective and $\leq 25 \mathrm{IU} / \mathrm{ml}$ were considered as non-protective. The sensitivity of the test was $100 \%$ with a specificity of $86 \%$. For both tests, ELISA plates were read in an ELISA reader (Labsystem, Multi Skan Ex, Finland) at 450/620 $\mathrm{nm}$ wavelength. Anti PT and anti FHA IgG antibody levels were evaluated using the Alisei Software 2.83 statistical analysis program.

\section{Statistical Analysis}

Statistical analyses were conducted by using SPSS 18 software. The suitability of representing the anti-PT and anti-FHA IgG antibody levels with a normal distribution was investigated by using visual (histogram, probability plots) and analytical (Kolmogorov-Simirnov) methods. Since the anti-PT and anti-FHA IgG antibody levels and logarithmic values did not match the normal distribution, the correlation coefficient for these parameters was calculated using the
Spearman test. Those with anti-PT antibody level> 11 NTU were considered immune. Chi-square and Fisher's exact test and Mann Whitney $U$ test were used for comparison purposes between groups and it was considered significant if the $\mathrm{p}$ value was less than 0.05 .

\section{Results}

Among the 133 patients included in this study $93(69.9 \%)$ were found to be immune according to anti-PT IgG antibody levels. On the other hand, according to anti-FHA IgG antibody levels, 123 participants (92.5\%) were found to be immune. A positive correlation was observed between anti PT and anti FHA, and the findings were statistically significant $(P<0.001, r=0.343)$ (Fig. 1).

In the study group, the ages of the participants varied between 17 and 44 years. The mean age $( \pm \mathrm{SD})$ of those who were immune was $27.3 \pm 5$.6, whereas the mean age of non-immune patients was $29.1 \pm 6.2$. This difference was not statistically significant $(P=0.14)$. Table I shows the two age groups above and below 30 years with their immune and non-immune percentages. It was observed that the immunity rates of age were similar to each other and were not statistically significant $(P=0.44)$. The highest number of patients were high school graduates according to their educational status, but the immune status in all groups was close to each other and

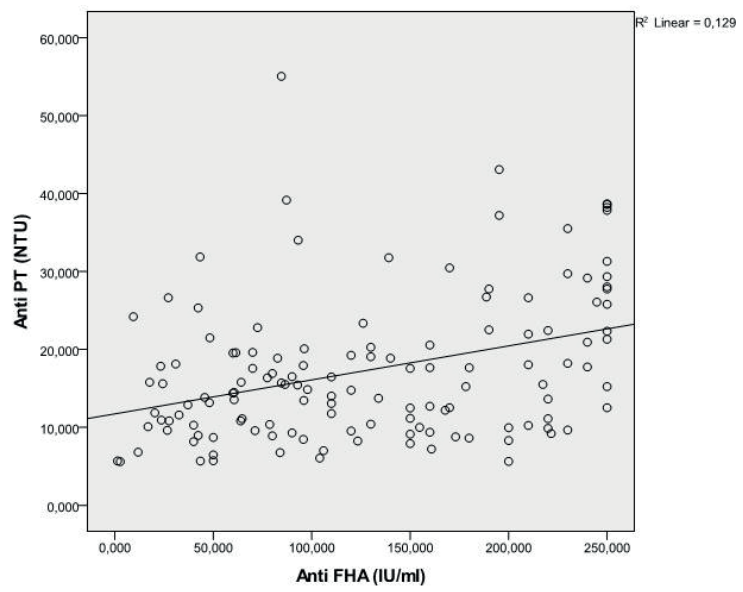

Fig. 1. Correlation of anti-PT with anti-FHA levels. 
Table I. Immunity according to patient demographics.

\begin{tabular}{|c|c|c|c|c|c|}
\hline \multirow{2}{*}{ Demographics } & \multicolumn{2}{|c|}{ Anti PT } & \multicolumn{2}{|c|}{ anti-FHA } & \multirow{2}{*}{$p$ values } \\
\hline & Immune (\%) & Non-immune (\%) & Immune (\%) & Non-immune (\%) & \\
\hline \multicolumn{6}{|l|}{ Age } \\
\hline $17-29$ & $57(73.1)$ & $21(26.9)$ & $76(97.4)$ & $2(2.6)$ & \multirow[t]{2}{*}{0.44} \\
\hline Above 30 & $36(65.5)$ & $19(34.5)$ & $47(85.5)$ & $8(14.5)$ & \\
\hline \multicolumn{6}{|l|}{ Education (n; \%) } \\
\hline Elementary school & $19(70.4)$ & $8(29.6)$ & $23(85.2)$ & $4(14.8)$ & \multirow{4}{*}{0.99} \\
\hline Secondary school & $14(70.0)$ & $6(30.0)$ & $17(85.0)$ & $3(15.0)$ & \\
\hline High school & $41(70.7)$ & $17(29.3)$ & $56(96.6)$ & $2(3.4)$ & \\
\hline University & $19(67.9)$ & $9(32.1)$ & $27(96.4)$ & $1(3.6)$ & \\
\hline \multicolumn{6}{|l|}{ Occupation (n; \%) } \\
\hline Employee & $14(70.0)$ & $6(30)$ & $19(95.0)$ & $1(5.0)$ & \multirow[t]{2}{*}{0.99} \\
\hline House-wife & 79 (69.9) & $34(30.1)$ & $104(92.0)$ & $9(8.0)$ & \\
\hline \multicolumn{6}{|l|}{ Pregnancy (n; \%) } \\
\hline First pregnancy & $36(69.2)$ & $16(30.8)$ & $46(88.5)$ & $6(11.5)$ & \multirow{3}{*}{0.98} \\
\hline Second pregnancy & $40(70.2)$ & $17(29.8)$ & $53(93.0)$ & $4(7.0)$ & \\
\hline Three or more & $17(70.8)$ & $7(29.2)$ & $24(100)$ & 0 & \\
\hline \multicolumn{6}{|l|}{ Vaccination history } \\
\hline Complete & $8(88.9)$ & $1(11.1)$ & $9(100)$ & 0 & \multirow{3}{*}{0.44} \\
\hline No vaccine & $4(66.7)$ & $2(33.3)$ & $5(83.3)$ & $1(16.7)$ & \\
\hline Can't remember* & $81(68.6)$ & $37(31.4)$ & 109 (92.4) & $9(7.6)$ & \\
\hline
\end{tabular}

$\mathrm{p}$ values were calculated according to anti PT levels.

*This group states that childhood vaccines are complete but do not remember their content.

the difference was not statistically significant (Table I). When the participants were examined according to their employement status (i.e. employed and housewives), the immune status was similar among the groups and the difference was not statistically significant. When the number of pregnancies of the participants were examined, it was observed that there was no correlation between the number of pregnancies and immune status (Table I).

It was found that $118(88.7 \%)$ patients had childhood vaccinations but could not remember whether DTaP vaccine was available. Immune status according to the childhood vaccination is given in Table I. Accordingly, there was no difference observed between the groups. It can be observed that there is a significant number of non-immune participants (40/133; 30.1\%), whose infants can be vulnerable to pertussis if not vaccinated immediately.

\section{Discussion}

Pertussis continues to cause deaths worldwide. According to the data from WHO, 16 million cases were seen only in 2008 and 195.000 of them were fatal. ${ }^{1}$ Infants are in the highest risk group in terms of severe pertussis and they usually get the disease from their adult relatives. ${ }^{23,24}$

Studies show that antibody levels begin to decrease and fall below the protective level 4-5 years after the acellular pertussis vaccine. ${ }^{1}$ Therefore, booster doses are needed for longterm immunity in adulthood. The ACIP, therefore, recommends routinely administering the Tdap vaccine to pregnant women since 2012 and repeating this vaccine in every subsequent pregnancy. ${ }^{1}$

Clinical studies are being conducted in the United States and many countries in Europe concerning the results of this vaccination. ${ }^{1}$ There 
is no routine recommendation of pertussis vaccine for adults and pregnant women in Turkey. ${ }^{6}$ The last dose of pertussis vaccine is applied in the first year of primary school (4-6 years old) resulting in a lack of adequate antibody levels in pregnant woman. Although contact with mild or asymptomatic pertussis cases in the society may provide protective antibodies against the disease, a significant part of the society remains susceptible to the disease in adulthood as corroborated with the data presented in the previous section. ${ }^{25-27}$

Studies showing immunity against pertussis in pregnant women are extremely limited in Turkey. In the study conducted by Ercan et al. ${ }^{19} 72 \%$ of pregnant women were found to be immune to pertussis. In our study, the immunity rate was similar $69.9 \%$. In studies conducted in other countries, the rates of immunity in pregnant women vary between $25 \%$ and $97.1 \% .15,16,27$ It is thought that this difference can be attributed to the differences in the vaccination programs, different probability of the prevalence of pertussis disease and differences in disease prevelance rates of different countries. ${ }^{3,12-14,16,17}$ Pertussis is usually diagnosed serologically or clinically. According to the Centers for Disease Control (CDC) and WHO, pertussis diagnosis can be established clinically in patients with cough for at least 14 days and the presence of at least one of the following symptoms: paroxysmal cough, postcough vomiting, or whooping sound in the inspiration. ${ }^{1}$ Serologically, antibodies against PT and FHA can be used in diagnosis. Antibodies against FHA antigens are not specific and may occur after Haemophilus influenza and Mycoplasma pneumonia infections, as well as other Bordetella infections. Antibodies developing against PT are specific for B. Pertussis and can be used in diagnosis. ${ }^{1}$ In our study, the level of immunity in patients was $69.9 \%$ according to anti-PT IgG antibodies and $92.5 \%$ according to anti-FHA IgG antibodies. In the light of this data, the immune ratio in pregnant women was accepted as $69.9 \%$. There is a rather limited number of studies investigating the level of immunity against pertussis in adults in Turkey. It has been shown that immunity rates vary between $58.1 \%$ and $72 \% .{ }^{16,19}$

Six of the patients (4.5\%) who participated in our study stated that their pertussis vaccine or childhood vaccines were not complete. Other patients reported that childhood vaccines were complete, although they did not remember exactly whether the whooping cough vaccination was complete. The coverage rate of pertussis vaccine between the years 2007-2018 in Turkey varies between $96-98 \%{ }^{23}$ This result is supported by the data presented herein with the rate of vaccination in pregnant women being $95.5 \%$. There was no significant difference in terms of pertussis immunity between the patients who stated that their vaccinations were not complete and who had complete their vaccines.

While the average age of patients with pertussis immunity was 27.3 years, the average age of those without immunity was 29.1 years. There was no significant difference in immunity levels when patients were divided into two age groups, over 30 years old and below 30 years old. The reason for this is interpreted as the fact that the current immunity in patients is caused by the cases of whooping cough they encounter in the community rather than the last pertussis vaccine that was applied at the age of 4-6. Similarly, Kurtoğlu et al. ${ }^{28}$ stated that protective antibody levels against whooping cough do not decrease in advanced age or even in the population above 70 years of age, which may be due to frequent contact with whooping cough.

The diagnosis of pertussis is difficult in adults and adolescents due to the mild and atypical symptoms, making it extremely challenging to determine the true incidence of the disease. The annual number of pertussis cases reported between 2009-2018 was between 11 and $322^{25}$ in Turkey. In a study by Sönmez et al. ${ }^{26}$ in adults with prolonged cough, pertussis was detected in $52(9.7 \%)$ of 538 patients. Similarly, in the study of Gürsel et al. ${ }^{29}$ in children with prolonged 
cough, pertussis was detected in 12 (23.5\%) of 51 patients. The data suggest that pertussis disease continues to be a common persistent public health problem in Turkey and the actual number of cases is significantly higher than reported. Hence, an improved public health policy regarding pertussis vaccination should be a Tdap vaccine administered in the second or third trimester during pregnancy which increases the number of antibodies in the mother and the fetus..$^{29,30}$ In some studies, it has been shown that deaths due to pertussis may decrease or even disappear in infants younger than six months of age if the administration of the Tdap vaccine in pregnant women becomes widespread..$^{30-32}$ The Tdap vaccine has been found to be safe in pregnant women and it has been reported that it does not increase the risk of hypertensive syndrome, chorioamnionitis, preterm delivery or low birth weight baby. ${ }^{14,33}$ In addition, the Tdap vaccine was found to be cost-effective. ${ }^{34}$

Controversy still exists regarding prenatal (After 27 weeks' gestation) or post-partum immunization (up to 14 days after delivery) in the literature. It is emphasized that women should receive the Tdap vaccine during pregnancy regardless of previous immunization history. Given prenatal or post-partum immunization of mothers and development of pertussis in infants, infants whose mothers received prenatal immunization had 50\% fewer cases of pertussis compared with those whose mothers received post-partum immunization. Results of cohort studies conducted in the USA and England showed that prenatal maternal Tdap vaccination is $91 \%$ effective in preventing pertussis during the first three months of life and $93 \%$ effective in preventing pertussis in the first eight weeks. ${ }^{31,35-37}$

In the USA, the National Advisory Committee on Immunization (NACI) and the ACIP of the $\mathrm{CDC}$ have recommended routine Tdap vaccination for adults. ${ }^{1}$ Additionally, experience in developed countries such as Canada and the USA has demonstrated that an adolescent pertussis vaccine program implemented on a national scale, is safe and can result in a further decrease in the incidence of pertussis. On the other hand, in line with the ACIP recommendation, studies on routine Tdap vaccination in pregnant women are in use in the USA, UK and some European countries. ${ }^{1-3}$ In our country, based on the previous data reflecting a significant number of pregnant women who are non-immune to pertussis, we recommend that the Tdap vaccine be implemented for pregnant women regardless of previous immunization history which in turn will be beneficial for the protection of infants in their first six months. Pertussis vaccination rate during pregnancy can be increased by the addition of Tdap vaccine in the routine vaccination schedule or national vaccination campaigns.

In conclusion, the present study revealed that approximately one third of pregnant women are not immune to pertussis, reflecting that newborn infants are vulnerable to pertussis infection. This data supports the need for pertussis vaccination with Tdap in the routine maternal immunization schedule for preventing infant infection in Turkey.

\section{Author contribution}

The contributions of all authors must be described in the following manner: The authors confirm contribution to the paper as follows: study conception and design: SG, SK; data collection: GA; analysis and interpretation of results: CS, GA, SG; draft manuscript preparation: SK, SG.

All authors reviewed the results and approved the final version of the manuscript.

\section{Ethical approval}

The study protocol was approved by the Clinical Research Ethics Committee of Kirıkkale University, 01/16.01.2020. 


\section{Source of funding}

The study receieved no funding.

\section{Conflict of interest}

The authors declare no conflict of interest.

\section{REFERENCES}

1. Waters $\mathrm{V}$, Halperin SA. Bordetella pertussis. In Bennet JE, Dolin R, Blaser MJ (eds). Mandell, Douglas, and Bennett's Principles and Practice of Infectious Diseases (8th ed) Vol 2, Chapter 232. Philadelphia: Saunders, 2015: 2619-2628e3. https:// doi.org/10.1016/B978-1-4557-4801-3.00232-0

2. Mooi FR, van Loo IH, King AJ. Adaptation of Bordetella pertussis to vaccination: a cause for its reemergence? Emerg Infect Dis 2001; 7(Suppl 3): 526-528. https://doi.org/10.3201/eid0707.017708

3. Mooi FR, de Greff SC. The case for maternal vaccination against pertussis. Lancet Infect Dis 2007; 7: 614-624. https://doi.org/10.1016/S14733099(07)70113-5

4. Subaiya S, Dumolard L, Lydon P, Gacic-Dobo M, Eggers R, Conklin L. Global routine vaccination coverage, 2014. MMWR Morb Mortal Wkly Rep 2015; 64: 1252-1255. https://doi.org/10.15585/mmwr. mm6444a5

5. WHO. Pertussis vaccines: WHO position paper, August 2015. Wkly Epidemiol Rec 2015; 90: 433-460.

6. Özbek ÖA, Öktem İMA, Hekimoğlu $\mathrm{CH}$, et al. Hücre içermeyen boğmaca aşı uygulamasının altıncı yılında Türkiye'nin Manisa ili'ndeki pertussis toksin antikoru seroprevalansı. Mikrobiyoloji Bülteni 2018; 52: 180-189. https://doi.org/10.5578/mb.57534

7. Republic of Turkey Ministry of Health. Health Statistics Yearbook 2018. Ankara: General Directorate of Health Information Systems, 2019. https://sbsgm. saglik.gov.tr/Eklenti/36164/0/siy2018en2pdf.pdf

8. Juretzko $\mathrm{P}$, von Kries R, Hermann M, Wirsing von König CH, Weil J, Giani G. Effec-tiveness of acellular pertussis vaccine assessed by hospital-based active surveillance in Germany. Clin Infect Dis 2002; 35: 162-167. https://doi.org/10.1086/341027

9. Quinn HE, Snelling TL, Macartney KK, McIntyre PB. Duration of protection after first dose of acellular pertussis vaccine in infants. Pediatrics 2014; 133: e513-e519. https://doi.org/10.1542/peds.2013-3181
10. Greenberg DP, von Konig CH, Heininger U. Health burden of pertussis in infants and children. Pediatr Infect Dis J 2005; 24 (Suppl 5): S39-S43. https://doi. org/10.1097/01.inf.0000160911.65632.e1

11. Forsyth K, Plotkin S, Tan T, Wirsing von König CH. Strategies to decrease pertussis transmission to infants. Pediatrics 2015; 135: e1475-e1482. https://doi. org/10.1542/peds.2014-3925

12. Villena R, Vidal P, Carrillo F, Salinas M. Pertussis vaccination in pregnancy: security and effectiveness in the protection of the infant. Rev Chil Pediatr 2017; 88: 318-323. https://doi.org/10.4067/S037041062017000300002

13. Van Rie A, Wendelboe AM, Englund JA. Role of maternal antibodies in infants. Pediatr Infect Dis J 2005; 24: S62-S65. https://doi.org/10.1097/01. inf.0000160915.93979.8f

14. Munoz FM, Bond NH, Maccato M, et al. Safety and immunogenicity of tetanus diphtheria and acellular pertussis (Tdap) immunization during pregnancy in mothers and infants: a randomized clinical trial. JAMA 2014; 311: 1760-1769. https://doi.org/10.1001/ jama.2014.3633

15. Abu Raya B, Srugo I, Bamberger E, Kessel A. The avidity of pertussis antibodies following gestational acellular pertussis immunization. Vaccine 2015; 33: 5490-5491. https://doi.org/10.1016/j. vaccine. 2015.05 .090

16. Fallo AA, Neyro SE, Manonelles GV, et al. Prevalence of pertussis antibodies in maternal blood, cord serum, and infants from mothers with and those without Tdap booster vaccination during pregnancy in Argentina. J Pediatric Infect Dis Soc 2018; 7: 11-17.

17. Kent A, Ladhani SN, Andrews NJ, et al; PUNS Study Group. Pertussis antibody concentrations in infants born prematurely to mothers vaccinated in pregnancy. Pediatrics 2016; 138: e20153854. https:// doi.org/10.1542/peds.2015-3854

18. de Greeff SC, de Melker HE, Westerhof A, Schellekens JF, Mooi FR, van Boven M. Estimation of household transmission rates of pertussis and the effect of cocooning vaccination strategies on infant pertussis. Epidemiology 2012; 23: 852-860. https:// doi.org/10.1097/EDE.0b013e31826c2b9e

19. Ercan TE, Sönmez C, Vural M, Erginoz E, Torunoğlu MA, Perk Y. Seroprevalance of pertussis antibodies in maternal and cord blood of preterm and term infants. Vaccine 2013; 31: 4172-4176. https://doi. org/10.1016/j.vaccine.2013.06.088 
20. Bigham M, Konrad S, Van Buynder P, et al. Low pertussis toxin antibody levels in two regional cohorts of Canadian pregnant women. Vaccine 2014; 32: 6493-6498. https://doi.org/10.1016/j. vaccine.2014.09.028

21. Healy CM, Munoz FM, Rench MA, Halasa NB, Edwards KM, Baker CJ. Prevalence of pertussis antibodies in maternal delivery, cord, and infant serum. J Infect Dis 2004; 190: 335-340. https://doi. org/10.1086/421033

22. Gonik B, Puder KS, Gonik N, Kruger M. Seroprevalence of Bordetella pertussis antibodies in mothers and their newborn infants. Infect Dis Obstet Gynecol 2005; 13: 59-61. https://doi. org/10.1080/10647440500068289

23. Türkoğlu E, Sönmez C, Özer E, Çöplü N, Kurugöl Z. Low pertussis antibody levels in maternal and umbilical cord blood samples in Turkey. Turk J Pediatr 2016; 58: 573-578. https://doi.org/10.24953/ turkjped.2016.06.001

24. WHO and UNICEF estimates of national immunization coverage. Available at: https://www. who.int/immunization/monitoring_surveillance/ data/tur.pdf (Accessed on May 15, 2020).

25. WHO vaccine preventable diseases: monitoring system 2019 global summary. Avaliable at https://apps.who.int/immunization_monitoring/ globalsummary/timeseries/tsincidencepertussis (Accessed on May 15, 2020).

26. Sönmez C, Çöplü N, Gözalan A, et al. Uzamış öksürügü olan erişkinlerde Bordetella pertussis enfeksiyonunun serolojik olarak değerlendirilmesi. Mikrobiyoloji Bülteni 2016; 50: 361-370. https://doi. org $/ 10.5578 / \mathrm{mb} .27692$

27. Narchi H, Osman W, George JA, Almekhaini LA, Souid AK, Alsuwaidi AR. Pertussis seronegativity in pregnant women in the city of $\mathrm{Al}$ Ain, United Arab Emirates. Int J Infect Dis 2019; 89: 96-101. https://doi. org/10.1016/j.ijid.2019.08.031

28. Kurtoğlu D, Gözalan A, Çöplü N, et al. Seçilmiş üç ilde boğmaca seroprevalansı ve aşılanma durumu. Mikrobiyoloji Bülteni 2008; 42: 389-398.

29. Gürsel D, Aslan A, Sönmez C, et al. Uzamış öksürüğü olan çocuklarda kültür, gerçek zamanlı polimeraz zincir reaksiyonu ve seroloji ile Bordetella pertussis enfeksiyonunun araştırılması. Mikrobiyoloji Bülteni 2012; 46: 211-224.
30. Eberhardt CS, Blanchard-Rohner G, Lemaitre B, et al. Maternal immunization earlier in pregnancy maximizes antibody transfer and expected infant seropositivity against pertussis. Clin Infect Dis 2016; 62: 829-836. https://doi.org/10.1093/cid/ciw027

31. Eberhardt CS, Blanchard-Rohner G, Lemaître B, et al. Pertussis antibody transfer to preterm neonates after second-versus third-trimester maternal immunization. Clin Infect Dis 2017; 64: 1129-1132. https://doi.org/10.1093/cid/cix046

32. Winter K, Nickell S, Powell M, Harriman K. Effectiveness of prenatal versus postpartum tetanus, diphtheria, and acellular pertussis vaccination in preventing infant pertussis. Clin Infect Dis 2017; 64: 3-8. https://doi.org/10.1093/cid/ciw634

33. Amirthalingam G, Andrews N, Campbell H, et al. Effectiveness of maternal pertussis vaccination in England: an observational study. Lancet 2014; 384: 1521-1528. https://doi.org/10.1016/S01406736(14)60686-3

34. Winter K, Cherry JD, Harriman K. Effectiveness of prenatal tetanus, diphtheria, and acellular pertussis vaccination in pertussis severity in infants. Clin Infect Dis 2017; 64: 9-14. https://doi.org/10.1093/cid/ ciw633

35. Sartori AMC, de Soárez PC, Fernandes EG, Gryninger LCF, Viscondi JYK, Novaes HMD. Cost-effectiveness analysis of universal maternal immunization with tetanus-diphteria-acellular pertussis (Tdap) vaccine in Brazil. 2016; 34: 15311539. https://doi.org/10.1016/j.vaccine.2016.02.026

36. Amirthalingam G, Campbell H, Ribeiro S, et al. Sustained effectiveness of the maternal pertussis immunization program in England 3 years following introduction. Clin Infect Dis 2016; 63(Suppl 4): S236-S243. https://doi.org/10.1093/cid/ciw559

37. Dabrera G, Amirthalingam G, Andrews N, et al. A case-control study to estimate the effectiveness of maternal pertussis vaccination in protecting newborn infants in England and Wales, 20122013. Clin Infect Dis 2015; 60: 333-337. https://doi. org/10.1093/cid/ciu821 